\title{
PROUNI: POLÍTICA DE ACESSO AO ENSINO SUPERIOR 10 ANOS DEPOIS
}

\author{
Valquíria Elita Renk ${ }^{1}$ \\ Ana Sílvia Juliatto Bordini ${ }^{2}$
}

\begin{abstract}
Resumo
Programa Universidade para Todos (PROUNI) está em vigência desde 2005 possibilitando o acesso às Instituições de Ensino Superior Privadas, dos estudantes de baixa renda, com a concessão de bolsas de Estudo. Neste artigo, buscou-se avaliar a eficácia do Programa através da situação socioeconômica de 352 egressos da área da saúde de uma Instituição de Ensino Superior privada de Curitiba, a qual recebe estudantes de todo país, no período de 2005 a 2015. É uma pesquisa de abordagem mista de caráter descritivo, e o instrumento de pesquisa é um questionário abrangendo questões sociodemográficas, a importância do PROUNI e quais as dificuldades encontradas para cursar a graduação. Os resultados demonstram que a maioria dos egressos é formada por mulheres, as quais estão inseridas no mercado formal de trabalho, na área de formação, recebem remuneração superior a cinco salários mínimos e são a primeira pessoa da família a concluir um curso superior. Os participantes relataram dificuldades para concluir o curso de graduação, como situações de preconceito e dificuldades financeiras. Este Programa promoveu o acesso e a conclusão do ensino superior a milhares de jovens de baixa renda, sua inclusão social, aumentando seu capital social, diminuindo as situações de vulnerabilidade social e promovendo dignidade humana. Mas ainda apresenta dilemas como a não garantia de permanência do estudante na instituição de ensino, a não ampliação de vagas em IES públicas e o benefício às instituições privadas de ensino com a isenção de impostos. Os resultados são discutidos na perspectiva interdisciplinar entre educação, sociologia e direitos humanos.
\end{abstract}

Palavras-chave: Educação. Políticas Públicas. Ensino Superior. PROUNI. Inclusão Social.

1 Doutorado em Educação pela Universidade Federal do Paraná (UFPR), docente titular Programa de Pós-Graduação em Bioética e Programa de Pós-Graduação em Direitos Humanos e Políticas Públicas da Pontifícia Universidade Católica do Paraná (PUCPR).valquiria.renk@pucpr.br

2 Mestre em Bioética pela Pontifícia Universidade Católica do Paraná (PUC-PR). asjuliatto@gmail.com 


\section{Introdução}

No Brasil, a educação é um direito social, garantido na Constituição Federal, no art. 6, cuja efetivação é através da implementação de políticas públicas (BRASIL, 1988). No país o número de pessoas que tem acesso ao ensino superior é de 17\%, segundo a Organisation for Economic Cooperation and Development(OCDE,2018a,2018b), pois historicamente a população de baixa renda foi excluída deste nível de ensino. O Programa Universidade para Todos (PROUNI) foi institucionalizado pela Lei ${ }^{\circ}$ 11.096/2005, como uma política pública do Governo Federal desenvolvida no domínio das universidades privadas, com o intuito de permitir o acesso ao ensino superior da população de baixa renda. Ela se efetiva com a concessão de bolsas de estudos integrais e parciais aos estudantes, em cursos de graduação e sequenciais de formação específica, na modalidade presencial ou a distância. As Instituições de Ensino Superior (IES) que aderem ao Programa recebem isenção de alguns tributos (BRASIL, 2018). Desde 2005 até 2018, o PROUNI já possibilitou que mais de 2,47 milhões de estudantes ingressassem no ensino superior.

Neste artigo, buscou-se avaliar a eficácia do Programa por meio da situação socioeconômica de 352 egressos da área da saúde. O recorte temporal é de 2005 a 2015, após dez anos de implementação do Programa, em uma Instituição de Ensino Superior particular de Curitiba ${ }^{3}$, mas os egressos são oriundos de diferentes regiões do Paraná e do Brasil. Optou-se por pesquisar os cursos na área da saúde por serem aqueles que têm o maior custo da mensalidade na instituição.

Considera-se que esta é uma pesquisa de relevância social, pois avalia a eficácia do Programa, dando voz aos egressos para que eles possam se manifestar quanto à sua situação social, econômica, externar dificuldades que vivenciaram para cursar a universidade e tecer críticas a esta política educacional. O PROUNI é um dos instrumentos para a democratização do acesso às Instituições de Ensino Superior e contribui para a dignidade humana, bem como com a mitigação do desrespeito aos Direitos Humanos. É uma política de ingresso, não garante a permanência do estudante na universidade, não aumentou o número de vagas nas universidades públicas e as instituições privadas ainda são maioria em ministrar o ensino superior no país. Os resultados da pesquisa são discutidos em perspectiva interdisciplinar nas interfaces entre educação, sociologia e direitos humanos.

O PROUNI é um tema bastante estudado, seja como uma política pública, na perspectiva da ampliação da educação superior, da educação, dos direitos humanos, como indicam alguns estudos: Bordini (2015), Chaves e Amaral (2016), Custódio (2019), Limena et al. (2011), Costa (2013), Costa e Ferreira (2017), Milanez (2016), Teixeira (2015), Saviani (2009, 2011), Valle (2009).
3 Projeto aprovado pelo Comitê de Ética Parecer no 459.479. As identidades dos participantes foram preservadas. 


\section{A sociedade brasileira e acesso desigual ao direito à educação}

A educação é um direito universal do ser humano, como estabelece o art. 26 da Declaração Universal dos Direitos Humanos (DUDH), e o acesso ao ensino superior deve ser aberto a todos em plena igualdade, em função do mérito individual (ONU, 1946). A Constituição do Brasil reforça a educação como um direito fundamental de natureza social (art. 6, 205 a 214) e o acesso aos níveis mais elevados será conforme a capacidade individual ( BRASIL, 1988) Rosa (2015) analisa que a Constituição elegeu a dignidade da pessoa humana como um dos cinco fundamentos do estado democrático e o direito à educação como um direito fundamental, o ensino é obrigatório gratuito como direito público subjetivo, um dever do Estado e um serviço público a ser prestado indiscriminadamente pelo poder público. "Não há nos dias atuais nenhuma carta de direitos, que não identifique o direito à instrução como integrante da construção do próprio estado de direito" (BOBBIO, 1992, p. 75).

A Lei no 9.394, de 20 de dezembro de 1996 - Lei de Diretrizes e Bases da Educação (LDB) - (BRASIL, 1996), universalizou a educação básica, e a educação aos níveis mais elevados (educação superior) será segundo a capacidade de cada um (art.3). Mas, no Brasil, o ensino superior é acessível à pequena parcela da população. Atualmente apenas $17 \%$ da população têm o ensino superior, o que representa pouco ante outros países. Por exemplo, no Chile esse índice é de 27\%; na Argentina, de 39\%; nos Estados Unidos, de 80\% (OCDE, 2018a, 2018b; ELY, 2019). Dos estudantes que concluíram o ensino médio na rede privada de ensino, $79,2 \%$ ingressam em um curso superior e os que frequentaram a rede pública de ensino, somente $36 \%$, o que revela a elitização do ensino superior. Sobre o perfil étnico racial, $51,5 \%$ dos que concluíram o ensino médio, eram brancos e 33,4\% negros e pardos (IBGE, 2018).

O Brasil é um país com grandes desigualdades sociais, ocupando a 79a posição mundial do IDH que é de 0,759 , segundo o Relatório do Desenvolvimento Humano do Programa das Nações Unidas para o Desenvolvimento (PNUD, 2018). Mais de um terço da população que nasce entre os $20 \%$ mais pobres permanece na parte inferior da pirâmide. Quanto à mobilidade social, $31 \%$ dos filhos que nascem entre os $20 \%$ mais pobres tendem a permanecer nesse grupo, e 17\% terão a ascensão à parte superior da pirâmide socioeconômica. Esta situação de baixa mobilidade e desigualdade social foi denominada pela OCDE (2018) como "chão pegajoso" (sticky floor), pela dificuldade que as famílias de baixa renda têm de sair da zona da pobreza e "tetos pegajosos" (sticky ceilings), que é a probabilidade de as crianças nascidas no topo da pirâmide viverem melhor que seus pais. 
Nesse sentido, as famílias que vivem na pobreza têm maiores probabilidades de ter menos anos de estudo, limitação com as opções de trabalho, empregos de baixa remuneração, aumentando a possibilidade de manutenção do ciclo de pobreza. Benedek, Moreira e Gomes (2014) caracterizam a pobreza como a condição humana marcada pela privação prolongada e crônica de recursos, capacidades, escolhas, segurança e poder necessários para desfrutar de um padrão de vida adequado, assim como a privação de direitos civis, culturais, econômicos e sociais. Também a falta de acesso representa um estado de vulnerabilidade, de violação dos direitos dos mais pobres de viver em segurança e com dignidade. É um estado de privação bem como de vulnerabilidade, que gera discriminação, viola os direitos dos mais pobres de viver em segurança e com dignidade.

Quanto à distribuição de renda em 2017, 10\% da população concentrava $43,3 \%$ da renda do País, enquanto os $10 \%$ mais pobres tinham apenas $0,7 \%$ da renda total (IBGE, 2018). Ainda, 4,8 milhões de pessoas sobrevivem com renda nominal mensal domiciliar igual a zero e 11,43 milhões de pessoas possuem uma renda de $R \$ 1,00$ por dia a $R \$$ 47,00 por mês, vivendo em condições de extrema pobreza, em situação de vulnerabilidade social Aproximadamente dois terços da população brasileira $(60,4 \%)$ não possui o ensino fundamental completo, tendo, no máximo, sete anos de escolaridade (IBGE, 2018). Nesse sentido, sem o princípio da dignidade enquanto fundamento da autoestima individual e do reconhecimento social, não existe sucesso na escola ou no mercado de trabalho (SOUZA, 2015; FOLMANN, 2018). A partir da abordagem dos direitos humanos, os miseráveis e os discriminados podem se mobilizar pelos seus direitos (SCHWARTZMAN, 2004).

A Declaração Universal dos Direitos Humanos, no art. 25, estabelece a necessidade da existência de um padrão de vida suficiente para o ser humano que possa lhe garantir saúde e bem-estar (ONU, 1948). Assim, a miséria e a exclusão social são violações da dignidade humana. No mesmo sentido, a Constituição Federal Brasileira, em seu art. $3^{\circ}$, estabelece a erradicação da pobreza e a redução das desigualdades sociais (BRASIL, 1988; preciso que estes princípios sejam garantidos através das políticas públicas. A pobreza se configura como a negação de oportunidades de ter vida longa e saudável, e de desfrutar de liberdade, dignidade, um padrão de vida decente, gerando vulnerabilidade social (SYMONIDES, 2003). A vulnerabilidade, a dignidade e a integridade são características descritivas dos seres humanos e que, embora não sejam normativas em si, são fundamentais para inspirar exigências éticas (HOSSNE 2009). O Estado existe em função dos cidadãos, deve protegê-los, garantir os direitos, especialmente dos vulneráveis e excluídos socialmente (SCHRAMM, 2011).

Nesse sentido, Custódio (2019), analisa que a desigual distribuição de renda transforma o Brasil em um país injusto, e que na educação se 
revela com escolas para os filhos da elite e para os pobres, acentuando as desigualdades sociais. A pobreza exclui os jovens da vida social e da escola. A escola cria formas de exclusão, porque os pobres são os que mais são excluídos do sistema escolar. As atitudes dos membros das diferentes classes sociais, assim como as atitudes a respeito da escola, da cultura escolar e do futuro oferecido pelos estudos expressam os sistemas de valores implícitos ou explícitos devido à posição social das famílias. As crianças da classe média são encorajadas pela família ao esforço escolar, tem o ethos de ascensão social e aspiração ao êxito (BOURDIEU, 2016) A classe média realiza maiores investimentos em educação, como um capital a ser herdado ou o efeito de inculcação exercido pela família e o efeito da trajetória social da experiência (BOURDIEU, 2008). Enquanto os operários não enviam seus filhos à escola pelo custo do investimento e por não ver chances de ascensão social. Dessa forma, os estudantes oriundos das famílias de baixa renda são marginalizados, enquanto são privilegiados os alunos mais dotados de capital cultural, pois as competências culturais e as atitudes cultas estão em correlação com a posse de títulos escolares (BOURDIEU, 2008).

Para o Bourdieu (2008), o sistema de ensino é aberto a todos; no entanto, reservado a alguns, reúne a aparência de "democracia", mas, dissimula a legitimação social. $\mathrm{O}$ capital cultural e o ethos concorrem para definir as atitudes diante da escola, que constituem o princípio da eliminação das crianças de diferentes classes sociais. O êxito escolar está ligado ao capital cultural legado pela família. Portanto, os jovens pobres são excluídos do sistema escolar ainda na educação básica, geralmente nem chegando ao nível superior. Nesse sentido, a teoria do capital cultural aborda que a pessoa que nasce em um ambiente com condições financeiras mais abastadas tende a receber ferramentas (acesso a bens culturais, tais como ir a cinema, museus, praticar esportes, outras línguas etc.) que a preparam para que suas habilidades e capacidades possam se desenvolver ao longo da sua vida e, consequentemente, tem mais chances de sucesso escolar (SOUZA, 2016; BOURDIEU, 2008, 2016).

Bourdieu (2016) discute que o capital cultural existe sob três formas: no estado incorporado que é inculcação e assimilação da incorporação, no estado objetivado através dos suportes materiais, dos textos escritos, das pinturas etc., e no estado permuta em capital econômico, benefícios simbólicos e materiais que o certificado escolar garante. Há uma relação entre o desempenho escolar e o capital escolar como capital cultural, pois as famílias de classe média fazem maiores investimentos culturais (frequência a museus, teatros, leituras e outros) que garantem maior sucesso escolar do que os filhos dos operários desprovidos deste capital cultural. Portanto, o peso relativo da educação familiar e da educação escolar varia segundo o grau de reconhecimento e ensino dispensado às diferentes práticas culturais 
(BOURDIEU, 2008). No Brasil, os menos favorecidos economicamente têm menos capital cultural; portanto, são excluídos do sistema escolar e do ensino superior.

O capital social está associado ao poder e à probabilidade de ganhos. Pode ser objetivado envolvendo propriedades materiais, ou incorporado envolvendo bens simbólicos ou culturais, como o prestígio social e também o diploma de curso superior (BOURDIEU, 2002). A distinção social proporcionada pela conclusão do curso de nível superior é pela ocupação, demarcando e diferenciando o trabalho intelectual de braçal. Assim, para os egressos do PROUNI, a posse do diploma em ensino superior significa a incorporação de um capital cultural que os diferencia das origens pobres e os aproxima das classes médias. $\mathrm{O}$ diploma universitário significa um grande capital social, um ganho cultural, o acesso ao saber científico, maior inserção no mercado de trabalho qualificado e melhores rendimentos. $\mathrm{O}$ capital cultural é acionado como uma arma na luta no campo de produção cultural e de classes sociais, à medida que é um capital incorporado (BOURDIEU, 2008).

\section{Ensino Superior e o PROUNI}

O PROUNI foi institucionalizado pela Lei no 11.096/2005, com a concessão de bolsas de estudo integrais e parciais em cursos de graduação em instituições de ensino superior privadas, que recebem em contrapartida isenção de tributos (BRASIL, 2019). Está inserido no Plano de Metas Compromisso Todos pela Educação (BRASIL, 2007a) do Plano de Desenvolvimento da Educação (PDE) (BRASIL, 2007b) com o objetivo de democratizar o acesso às instituições privadas de educação superior (SAVIANI, 2009). Como uma política de inclusão social contempla a população situada em determinadas faixas de renda, a população de baixa renda que historicamente era excluída do ensino superior (ALMEIDA et al., 2010; LIMENA et al., 2011).

A educação é uma ferramenta sólida para que o indivíduo atinja o seu desenvolvimento e a sua emancipação (CANDIOTTO; CUSTÓDIO, 2017). O direito à educação é uma oportunidade de desenvolvimento do cidadão, um caminho de diversas opções e uma chave crescente de estima para si mesmo (CURY, 2002, 2005). O acesso limitado ao ensino superior contribui para a manutenção da situação de desigualdades, cabendo ao Estado a formulação de políticas públicas de inserção e manutenção dos vínculos sociais (PIOVESAN,2008,2014; CUSTÓDIO,2019; PAUGAM, 2003). O Ensino Superior poderá ser uma mola propulsora, tornando os sujeitos aptos para mudarem a sua realidade, tendo mais escolhas e oportunidades, diminuindo as desigualdades sociais e contribuindo para a mitigação das infringências dos direitos humanos. A consolidação da 
democracia pressupõe uma agenda de inclusão social e a prevalência dos direitos humanos. (GALLARDO, 2014, SANTOS, 2007).

No Brasil e na América Latina, desde o final do século XX o ensino superior passa pela tendência mercantilizante da universidade pública e a comoditização da educação privada, como reflexo da expansão das universidades privadas (SERAFIM, 2011). A privatização do ensino superior no Brasil vem sendo utilizada com a finalidade de reduzir a presença do Estado na área social (RODRIGUES, 2007). A expansão do ensino superior ocorreu com o aumento das IES privadas, que tornaram a "educação um bem ou "produto", que os "clientes" adquirem no "mercado universitário" (CATANI; OLIVEIRA, 2007, p. 83).

Em 2005, ano de implantação do PROUNI, no Brasil havia 2.165 instituições de ensino superior, sendo 1.934 privadas, e 231 privadas, totalizando 4.567.798 matrículas (BRASIL, 2007). Em 2015 havia 2.364 IES, sendo 2.069 privadas e 295 públicas, e o número de matrículas era de 8.531.655 (BRASIL, 2018). Ressalta-se que há mais IES privadas em razão da não oferta da totalidade da demanda do ensino superior por parte do Estado (SACAVINO; CANDAU, 2008; MALISKA, 2001).

Considerando que as IES públicas não atendem toda a demanda pelo acesso ao ensino superior, muitos candidatos de baixa renda buscam ingressar em instituições privadas, através do Financiamento Estudantil (FIES) e do PROUNI (SAVIANI, 2009). Por isso, o acesso ao ensino superior nas instituições privadas aumentou significativamente com o PROUNI; ademais, o governo diminuiu os gastos públicos e os investimentos em políticas sociais. (CHAVES, 2010; CHAVES; AMARAL, 2016).

Ante a esse quadro do ensino superior no Brasil, o PROUNI já atendeu, desde 2005 até o segundo semestre de 2018, mais de 2,47 milhões de estudantes, sendo 69\% com bolsas integrais (BRASIL, 2019). Esse Programa insere-se nas políticas públicas de acesso ao ensino superior, fundamentando-se na "[...] redistribuição indireta de renda [...] que incorpora os setores tradicionalmente excluídos da educação superior: a população de baixa renda proveniente das escolas públicas, no que se inclui a população negra e grupos étnico-raciais” (GOMES, 2008, p. 29). Compreende-se por política pública "[...] a somatória das atividades dos governos, que agem de forma direta ou através de representação, influenciando a vida dos cidadãos, refletindo na economia e nas sociedades" (SOUZA, 2006). As políticas públicas são ações e programas desenvolvidos pelo Estado, criadas para suprir alguma necessidade social, para garantir e colocar em prática direitos constitucionais e de outras leis (DI GIOVANNI, 2009). Boneti (2003) e Boneti, Gisi e Filipak (2013) analisam que, na implantação das políticas públicas, há uma correlação de forças, um jogo de poderes, de interesses entre grupos econômicos e 
políticos, classes sociais e demais interessados. O resultado é a ação que será repassada pela máquina estatal à sociedade civil.

O PROUNI tem abrangência nacional, envolvendo o Ministério da Educação, que organiza, executa e fiscaliza as IES privadas que ofertam as vagas e recebem isenção de impostos (IRPJ, PIS, COFINS e CSLL) e os estudantes com renda familiar de no máximo 1,5 salários mínimos, para a concessão da bolsa integral e até 03 salários mínimos no caso de bolsa parcial de 50\%, desde que, egressos do ensino médio da rede pública ou da rede privada na condição de bolsistas e outros critérios ${ }^{4}$ (GUIMARÃES; SANTOS, 2011).

Todavia, convém esclarecer que essa política garante o acesso, mas não assegura a permanência do estudante na IES até a conclusão do curso. A té 2018, mais de 2,47 milhões de estudantes ingressaram no ensino superior pelo PROUNI; destes, 69\% com bolsa de estudo integral (BRASIL, 2019). Quando iniciou, em 2005, foram ofertadas 112.275 bolsas de estudo. Em 2018, foram concedidas 417.278 bolsas, demonstrando que o Programa continua em crescimento. A cada ano, milhares de jovens passam a ter acesso às IES e, consequentemente, aos saberes técnicos e científicos, o que ao mesmo tempo os prepara para o mundo do trabalho (SPELLER; ROBL; MENEGHEL, 2012).

Mari (2011) analisa que esta política, ao conceder as bolsas de estudo, promove a inclusão social das camadas de baixa renda, aumenta o contingente de estudantes que frequentam o ensino superior e também beneficia as instituições privadas que tinham vagas ociosas. Assim, a expansão do ensino superior no Brasil, precisa incorporar os segmentos tradicionalmente excluídos desse nível de ensino e "[...] pode favorecer a concretização de sonhos, a construção de saberes, possibilitando também que a universidade privada brasileira possa objetivar sua função social, ao promover a educação e elevar o nível de qualificação profissional"(LIMENA et al., 2011, p. 9). Entretanto, ao mesmo tempo em que amplia o acesso da população de baixa renda às IES privadas, exime o governo de investir em vagas no ensino superior público (CATANI; HEY; GILIOLI, 2006).

$\mathrm{O}$ acesso ao ensino superior é importante para o desenvolvimento de um país, pois sem este nível de educação, há o retardo de produção de novas tecnologias, novas políticas e de inovação (SILVA, 2007, CHIARINI; VIEIRA, 2012). Assim, as IES têm importante papel seja na formação de profissionais, quadros administrativos e lideranças sociais, atuando também como um mecanismo de ascensão social (SEVERINO, 2008).

Apesar da inclusão de milhares de estudantes ao ensino superior, esta política é criticada como compensação de uma dívida pública herdada anteriormente, relacionada à falta de investimentos em educação e formação de mão de obra, ao mesmo tempo em que beneficia as IES privadas, com
4 Para saber os critérios estabelecidos em legislação própria do Sistema PROUNI e o perfil completo dos candidatos ao PROUNI, acessar: http://prouniportal.mec.gov.br 
5 Utilizou-se o banco de dados da Instituição de Ensino Superior da cidade de Curitiba mediante autorização através do Termo Compromisso de Utilização de Dados (TCUD) para ter acesso aos dados dos egressos, assim como o correio eletrônico para o envio do instrumento de pesquisa. Os participantes também concordaram com o Termo de Consentimento Livre e Esclarecido (TCLE), o qual garante o sigilo da identidade, conforme Resolução CNS n 466 de 2012 . isenção de tributos (MANCEBO, 2004; BORDINI, 2015). Mas, apesar destas contradições, Saviani (2011) analisa que a educação consiste na condição necessária para o exercício de todos os direitos: civis, sociais, econômicos ou políticos. Logo, o acesso à educação, em especial ao ensino superior, é fundamental para a garantia dos direitos dos cidadãos.

A IES objeto desta pesquisa é uma instituição filantrópica, regida pela Lei no 12.101, de 27 de novembro de 2009, esta que, no art. 13, determina o número de alunos com bolsa integral do PROUNI na proporção de 1 para 4 (bolsas obrigatórias) e a proporção de 1 para 9 (bolsas adicionais não obrigatórias). A política educacional brasileira, como analisa Saviani (2014, apresenta-se com características condensadas nas palavras: filantropia, protelação, fragmentação e improvisação. Para o autor, o Estado é o regulador da educação, mas transfere para a sociedade as responsabilidades pela sua manutenção e garantia de qualidade. Desde a criação do PROUNI, em 2005, até 2015 ingressaram na IES objeto desta pesquisa em torno de 70.000 estudantes, e destes 13.500 estudantes (19\%) ingressaram por meio do PROUNI.

\section{Resultados e análise da pesquisa}

Após de dez anos de implementação do PROUNI, considerou-se que era oportuno e necessário avaliar se os objetivos propostos por este Programa estavam sendo alcançados. Para isso, selecionou-se uma IES particular de Curitiba ${ }^{5}$ para ser o campo de investigação, mas, que atende estudantes em nível local, regional e nacional. O recorte tempo iniciou no ano de 2005, com adesão do PROUNI na IES até o ano de 2015 quando já havia razoável número de concluintes deste Programa, período em que se considera possível avaliar as condições socioeconômicas dos egressos.

Esta é uma pesquisa na perspectiva social realizada com os egressos do PROUNI. De abordagem mista (os dados coletados foram quantificados e analisados de forma qualitativa) e de caráter descritivo. Foram selecionados para participar da pesquisa os egressos dos seguintes cursos da área da Saúde: Medicina, Odontologia, Ciências Biológicas, Educação Física, Enfermagem, Farmácia, Fisioterapia, Nutrição, Psicologia e Tecnologia em Gastronomia, que, são os que têm o maior custo da mensalidade na instituição e menos acessíveis à população de baixa renda. Para viabilizar a coleta de dados, foi elaborado um questionário, que foi enviado ao endereço do correio eletrônico da totalidade dos egressos do PROUNI da IES participante da pesquisa, que são 421 egressos, mas o questionário foi respondido por 352 sujeitos. Nesta pesquisa os egressos tiveram voz e puderam se manifestar quanto à sua situação socioeconômica antes e depois de concluído o curso superior, suas percepções sobre o PROUNI e sobre a vivência escolar. 
O instrumento de pesquisa é um questionário é composto de 24 questões, com questões demográficas identificando o perfil do participante (idade, sexo (gênero), local de moradia); o perfil socioeconômico (emprego, área de trabalho e salário) e também o relato das dificuldades encontradas para cursar a graduação (financeiras, transporte, moradia, relações sociais, preconceitos). Os resultados foram sistematizados e categorizados em: a) Perfil Demográfico dos Egressos, b) As Condições socioeconômicas dos egressos, c) A importância e as dificuldades encontradas pelos bolsistas PROUNI e d) Preconceitos vividos no período universitário, que são analisados a seguir.

\section{a) Perfil Demográfico dos Egressos}

A primeira parte do instrumento de pesquisa era composta por questões de identificação, que possibilitam traçar um perfil demográfico dos egressos participantes da pesquisa, tais como: qual foi o curso concluído, modalidade de bolsa recebida, sexo/gênero, idade, estado civil e local de origem, que são apresentados na Tabela 1 .

Tabela 1 - Perfil dos Egressos

\begin{tabular}{|c|c|c|c|c|c|c|}
\hline $\begin{array}{l}\text { Curso } \\
\text { concluído }\end{array}$ & $\begin{array}{l}\text { Local de origem } \\
\text { (maioria dos } \\
\text { egressos do } \\
\text { curso) }\end{array}$ & $\begin{array}{l}\text { Gênero* } \\
\text { (maioria dos } \\
\text { egressos do } \\
\text { curso) }\end{array}$ & $\begin{array}{l}\text { Faixa } \\
\text { etária } \\
\text { anos }^{* *}\end{array}$ & $\begin{array}{c}\% \text { de } \\
\text { Concluintes } \\
\text { no total de } \\
\text { pesquisados }\end{array}$ & $\begin{array}{l}\text { Bolsa Parcial } \\
\text { ou Integral (a } \\
\text { maioria dos } \\
\text { egressos por } \\
\text { curso) } \\
\end{array}$ & $\begin{array}{c}\text { Trabalha na área de } \\
\text { formação (a maioria } \\
\text { dos egressos por } \\
\text { curso) }\end{array}$ \\
\hline $\begin{array}{l}\text { Educação } \\
\text { Física }\end{array}$ & Curitiba & Masculino & $25-30$ & $17 \%$ & Integral & Parcialmente \\
\hline Biologia & Paraná & Feminino & $25-30$ & $15 \%$ & Parcial & Parcialmente \\
\hline Nutrição & Paraná & Feminino & $18-24$ & $5 \%$ & Integral & Sim - totalidade \\
\hline Psicologia & $\begin{array}{l}\text { Curitiba } \\
\text { e Região } \\
\text { Metropolitana de } \\
\text { Curitiba }\end{array}$ & Feminino & $25-30$ & $9 \%$ & Integral & Parcialmente \\
\hline Medicina & Brasil & Masculino & $25-30$ & $13 \%$ & Integral & Sim - totalidade \\
\hline Enfermagem & Curitiba & Feminino & $25-30$ & $8 \%$ & Integral & Parcialmente \\
\hline Farmácia & Curitiba & Feminino & $25-30$ & $13 \%$ & Integral & Parcialmente \\
\hline Fisioterapia & Curitiba & Feminino & $18-24$ & $5 \%$ & Integral & Sim - totalidade \\
\hline $\begin{array}{l}\text { Técnico em } \\
\text { Gastronomia }\end{array}$ & Curitiba & Feminino & $18-24$ & $5 \%$ & Parcial & Parcialmente \\
\hline Odontologia & Brasil & Feminino & $18-24$ & $10 \%$ & Integral & Sim - totalidade \\
\hline
\end{tabular}

* Foram dadas as opções de feminino, masculino, outro; ** faixas etárias de 18 a 24 anos e 25-20 ou mais anos.

Fonte: Elaborada pelas autoras (2015). 
Os resultados da Tabela 1 mostram que os participantes são majoritariamente do gênero feminino (87\%), exceto nos cursos de Medicina e Educação Física, são solteiras (60\% das respondentes), jovens adultos com idades entre 25 a mais de 30 anos de idade, residentes em Curitiba e Região Metropolitana de Curitiba, e a maioria recebeu bolsa integral de estudos (95\%). Os cursos considerados que têm as mais altas mensalidades (Medicina e Odontologia) com 23\% dos respondentes oriundos de outras regiões do Brasil, mostrando a abrangência nacional do Programa, mas, a IES também tem uma grande influência regional, pois recebe estudantes de todo o Paraná, com 20\% dos respondentes (cursos de Biologia e Nutrição). A IES pesquisada tem grande influência em Curitiba e Região Metropolitana, totalizando 57\% dos respondentes, mostrando que os impactos de formação refletem em nível regional e nacional.

\section{b) As Condições Socioeconômicas dos Egressos}

A pesquisa comparou as condições socioeconômicas dos participantes, antes do ingresso na IES e depois da conclusão do curso, para poder avaliar se houve incorporação ao mercado de trabalho e qual é a atual sua situação financeira.

Os resultados da pesquisa mostram que antes de ingressar no PROUNI, 56\% dos respondentes eram estudantes; 34\%, estavam empregados com registro em carteira; 7\%, estavam desempregados; $3 \%$, eram estagiários. Do total de respondentes, $87 \%$, tinham uma renda pessoal mensal bruta de até 1,5 salários mínimos; 13\%, de até 3 salários mínimos. A partir desses dados, torna-se possível identificar que esses estudantes viviam em situação de pobreza, vulnerabilidade e exclusão social.

A maioria dos egressos (94\%) está exercendo atividade profissional, e $41 \%$ deles declararam estar empregados com registro em carteira, 32\% estão inseridos no mercado de trabalho como autônomos (são profissionais liberais); $21 \%$ são funcionários públicos e $6 \%$ encontram-se na condição de desempregados. Do total dos pesquisados, $80 \%$ estão exercendo atividade profissional relacionada à sua área de formação. Os oriundos dos cursos de Medicina, Fisioterapia, Nutrição e Odontologia em sua totalidade estão exercendo atividades relacionadas às suas áreas de formação. Ao exercerem a profissão relacionada à sua formação, demonstram a inserção do mercado de trabalho de forma mais qualificada, maior emancipação financeira, ascensão social, distinção profissional, prestígio social e diferenciação com a origem familiar (MILANEZI, 2016). Receber maiores rendimentos representa ter acesso a bens e serviços não vislumbrados no período anterior ao ingresso na IES.

Após a conclusão do curso superior, a renda dos participantes da pesquisa aumentou, visto que $41 \%$ dos respondentes têm uma renda mensal 
bruta atual de até 5 salários mínimos; 30\%, até 3 salários mínimos; 17\%, superior a 6 salários mínimos, e $12 \%$ deles têm renda mensal atual de até 1,5 salários mínimos. Destes, os egressos do Curso de Medicina informam ter rendimentos acima de 6 salários mínimos; os de Ciências Biológicas declaram ter rendimentos de até 3 salários mínimos, enquanto os egressos dos demais cursos pesquisados relatam possuir rendimentos de até 5 salários mínimos. Estes dados mostram que houve um incremento na renda após a conclusão do ensino superior, ocasião em que saíram da situação de vulnerabilidade social.

Os resultados mostram que os participantes foram inseridos no mercado formal de trabalho com melhoria na renda individual, aumentando a sua inserção social, econômica e educacional, com maiores possibilidades de mobilidade social e aumento da dignidade humana (GARRAFA; PESSINI, 2004; SCHRAMM, 2011; COSTA, 2012). Portanto, podese considerar que indiretamente os participantes da pesquisa obtiveram o ganho de capital objetivado (que são os bens materiais) e também capital incorporado (que são os bens simbólicos, como o prestígio social no seu grupo) (BOURDIEU, 2008).

A maioria dos participantes (66\%) relatou ser a primeira pessoa da família a concluir um curso superior, cujo diploma representa uma conquista individual, da família e é um símbolo de ascensão social. Bourdieu (2008) analisa que a instituição escolar ou acadêmica tem o monopólio da certificação através do diploma, que é a conversão do capital cultural herdado em capital escolar. Assim, existem os efeitos da imposição simbólica do diploma, que se estende muito além do conhecimento técnico e das competências. Ter o diploma de um curso superior assegura as competências específicas e também a posse de uma cultura que demonstra o prestígio social (BOURDIEU, 2008). Portanto, a mobilidade individual é produto do sistema de ensino, cujo diploma representa a incorporação das capacidades técnicas, e da transformação dos postos de trabalho com a ocupação de cargos mais qualificados e mais bem remunerados.

Para os participantes, a experiência da vivência universitária os fez adquirir e incorporar novos hábitos os habitus de classe, como o modo de falar, agir, significando uma forma incorporada da condição de classe, um ganho de capital cultural e também os aproximando do modo de vida da classe média (BOURDIEU, 2008). Além disso, ganharam competências teóricas, passando a diferenciá-los do seu grupo social e familiar, o ganho de um capital escolar que passa a expressar a sua nova condição social e econômica, mudando os comportamentos com a inculcação de novos hábitos que denotam a ascensão social.

Por outro lado, para 34\% dos egressos já existem na família outras pessoas que haviam concluído um curso superior. Bourdieu (2008) analisa 
que o diploma tem grande poder simbólico transformando a escola em uma das instâncias sine qua non da manutenção da ordem social. Desse modo, a obtenção do diploma, significa a mudança de status social, de passar da condição de menos instruído para a de mais instruído, de ter competência intelectual e possibilidades de mobilidade social.

Os resultados da pesquisa mostram que esta é uma política pública de inclusão social e de distribuição indireta de renda pela inclusão de pessoas alijadas socialmente pela sua condição social e que sofreram várias formas de discriminação por sua condição social. (GOMES, 2008; TEIXEIRA, 2015; LIMENA et al., 2011).

\section{c) A importância e dificuldades encontradas pelos bolsistas PROUNI}

Os egressos avaliam muito bem e têm uma percepção deste Programa. Quando foram questionados sobre a importância do PROUNI em sua vida e na formação acadêmica, a maioria (89\%) declarou como muito importante, pois sem o Programa esses estudantes não teriam cursado uma graduação e $11 \%$ informam que o programa foi importante. Esta atribuição de valor demonstra a eficácia da política pública de inserção social. Este Programa vem confirmar que o papel do Estado está na promoção da justiça mitigando as desigualdades, promovendo o acesso à equidade social através das políticas públicas (RIZZOTTO; BORTOLOTO, 2011).

Apesar dos resultados desta pesquisa, ainda é pouco o tempo para dimensionar os impactos nacionais alcançados pelo PROUNI na diminuição das desigualdades sociais na sociedade brasileira (SOUZA, 2016). Lembrando que toda política pública tem como fator-chave preencher lacunas referentes às necessidades da sociedade, principalmente a parcela que se encontra vulnerável (BONETI; GISI; FILIPAK, 2013).

$\mathrm{Na}$ trajetória da formação acadêmica, os pesquisados revelaram as dificuldades encontradas para concluir o curso superior. As maiores dificuldades relatadas foram dificuldades financeiras (34\%), custear o transporte (28\%), entrosamento com os colegas (14\%), dificuldades em relação ao acompanhamento acadêmico (9\%), em arcar com os custos da moradia (5\%). As maiores dificuldades estão relacionadas aos aspectos econômicos, as quais, se não forem solucionadas, podem levar o estudante a abandonar a formação. Pode-se inferir que muitas dificuldades poderiam ser sanadas se o PROUNI ou a IES disponibilizasse algum incentivo à permanência na instituição até o aluno concluir o curso universitário, em uma perspectiva de humanização (SACAVINO; CANDAU, 2008). Para os cursos com carga horária superior a 6 horas diárias, existe a possibilidade de recebimento de um auxílio mensal de $R \$ 400,00$ para pagamento de gastos relativos a transporte, alimentação e material didático, como proposto na Lei no 11.1802005 , alterada pela Lei no $12.431 / 2011$. É de 
grande importância que este benefício seja estendido, também, para os demais estudantes que tenham carga horária diária abaixo de seis horas diárias. Caso persistam as dificuldades de permanência no ensino superior, ficam dúvidas sobre a possibilidade de usufruir de maneira plena a vida acadêmica (MILANEZ, 2016).

A experiência social e histórica da vida universitária mostra que muitas questões sociais subjetivas estão presentes na universidade e podem levar os estudantes a situações de constrangimento. Nesse sentido, podese inferir que, quando os participantes relataram falta de entrosamento, podem estar se referindo também à percepção das diferenças de capital cultural (BOURDIEU, 2008, 2016).

Assim, uma IES que se pretende inclusiva, precisa educar para os Direitos Humanos, reconhecer as diferenças sociais, culturais e econômicas, aceitar a pluralidade cultural e propiciar condutas nas quais prevaleça o valor da pessoa humana (AGUIRRE, 2007). Portanto, são muito importantes as políticas públicas que garantam os Direitos Fundamentais Sociais, que tragam respostas aos direitos das pessoas historicamente marginalizadas ou desrespeitadas em algum aspecto da sua dignidade na dimensão históricocultural (SARLET, 2010).

\section{d) Preconceitos vividos no periodo universitário}

Sobre os egressos terem sofrido algum preconceito no período em que cursavam o curso universitário, a maioria $78 \%$ dos egressos declaram não ter sofrido nenhum tipo de preconceito; mas, 22\% declaram que sofreram preconceito, constrangimento ou discriminação. A trajetória acadêmica é marcada pela experiência, que se constrói no dia a dia, repleta de valores sociais e simbólicos. Nesse sentido, as marcas do pertencimento social estão expressas no que Bourdieu $(2008,2016)$ analisou como o "gosto" ou o "bom gosto" que traz elementos que denotam o capital cultural objetivado e o peso relativo da educação familiar e escolar atribuídas conforme o reconhecimento às práticas culturais. Portanto, estar na mesma IES não apaga as origens sociais, os investimentos que a classe média faz no capital escolar, contrastando com os estudantes das classes menos privilegiadas que são desprovidos deste capital cultural e os estudantes muitas vezes sentemse estigmatizados.

As diferenças econômicas são ampliadas pelas distinções simbólicas (vestuário, linguagem etc.), que são traços que simbolizam a posição social do sujeito na estrutura social, e há correlação entre o capital escolar como capital cultural reconhecido e garantido pela instituição escolar. Portanto, as instituições escolares inculcam valores que se constituem em uma cultura dominante, legítima, a propósito dos “[...] saberes e das práticas escolarmente reconhecidos tende a aplicar-se além dos limites escolares" 
(BOURDIEU, 2008, p. 27). Para Bourdieu, a lógica da distinção aplica-se a um sistema de inclusão e exclusão, que são as relações entre os aspectos simbólicos e econômicos que se expressam em um estilo de vida. Os sistemas simbólicos (estruturas de semelhança e oposições) realizam a função social de associação ou dissociação da sociedade enquanto sistema de significações.

Nem sempre o preconceito e a discriminação são visíveis. Muitas vezes se apresentam de forma dissimulada e subjetiva. Bourdieu (2005) permite analisar que as diferenças econômicas são ampliadas pelas distinções simbólicas no consumo dos bens de consumo em signos, que podem ser apresentados como uma "estilização da vida" e se torna visível com traços distintivos que simbolizam a posição social, privilegiando o modo de agir que se manifesta no vestuário, na linguagem e outros. Portanto, os participantes da pesquisa demonstraram que existem sinais visíveis de distinção social, e os sistemas simbólicos realizam a função de associação ou dissociação. $\mathrm{O}$ preconceito também demonstra as desigualdades sociais, as situações de vulnerabilidade às quais estamos sujeitos em razão da condição econômica, social e do grau de escolaridade (HOSSNE, 2009).

Os resultados desta pesquisa são significativos, pois os egressos tiveram o direito de fala e puderam se manifestar quanto a esta política e indicar propostas de mudanças. Os egressos do PROUNI poderão, em igualdade de condições, buscar melhores condições de vida; neste sentido, a infringência aos direitos humanos passa a ser mitigada (LUCRI, 2016, CUSTÓDIO, 2019). O PROUNI apresenta potencial de promoção da democratização do acesso à educação superior, aos jovens alijados socialmente por sua condição financeira, diminuindo o seu caráter elitista das IES (MARQUES, 2015).

Embora o Estado brasileiro não tenha o caráter de obrigatoriedade do fornecimento da educação em nível superior pelo Estado, o maior acesso e conclusão atendem aos objetivos do estado democrático, como proposto na Constituição Federal, no art. 1 $^{\circ}$, inciso II e III (estabelece a cidadania e dignidade da pessoa humana); art. $3^{\circ}$, incisos I, II, III e IV (estabelece a construção de uma sociedade livre justa e solidária; garante o desenvolvimento nacional, a erradicação da pobreza e a marginalização e a redução das desigualdades sociais e regionais; a promoção do bem de todos, sem preconceito de origem, raça, sexo, cor, idade e quaisquer outras formas de discriminação); e capítulo III, a Educação, compreendendo os arts. 205 a 214 (incluindo o tratamento para o ensino superior) (BRASIL, 1988; TEIXEIRA, 2015).

A pesquisa demonstra que o PROUNI apresenta deficiências, tais como: A) O Programa é uma forma de repassar um dever do Estado, que é o direito a educação a todos, para a iniciativa privada; B) Ao repassar esta 
obrigação do Estado à iniciativa privada em troca de isenção de tributos, como afirma Saviani (2011), ocorre a mercantilização do Ensino Superior; C) O PROUNI possibilita o acesso aos estudantes; porém, não garante a permanência e a conclusão do Ensino Superior. Estas deficiências analisadas remetem à necessidade de uma reavaliação destes aspectos do Programa para sua melhor funcionalidade e abrangência. Pode-se refletir que as políticas de acesso ao ensino superior, não mudaram a estrutura social que as engendrou, persistindo a busca da justiça social e da redução das desigualdades sociais. Sobre esse assunto, Piovesan (2008) analisa que há a necessidade de formação de uma cultura de Direitos Humanos, que promova o desenvolvimento da personalidade humana, senso de dignidade a ponto de possibilitar que os cidadãos participem de uma sociedade livre e democrática.

Apesar de sua abrangência, o PROUNI destinou apenas 1\% das bolsas de estudo aos professores (TEIXEIRA, 2015), o que reduz significativamente o aspecto da qualidade do ensino e da qualificação dos professores da educação básica.

\section{Considerações finais}

Os resultados desta pesquisa possibilitaram avaliar a eficácia do PROUNI, através da fala dos egressos. A maioria das participantes são mulheres, jovens adultas, mostrando a incorporação deste segmento social, o qual era marginalizado socialmente, tendo concluído o curso com bolsa integral. Considerando o perfil dos candidatos ao PROUNI, os cursos da área da área da saúde têm mensalidades elevadas, o que impossibilita o ingresso da população de baixa renda. A maioria das entrevistadas está empregada em sua área de formação, recebendo remuneração melhor do que quando ingressou na universidade, demonstrando que houve a incorporação de capital cultural, ascensão social e profissional, que foi rompida a situação de pobreza e houve redução das condições de vulnerabilidade social. Estes resultados indicam impactos positivos como a formação acadêmica, a qualificação para o mercado de trabalho, o crescimento profissional, a elevação de renda, a ascensão social, o ganho de prestígio social, a distinção profissional e a diferenciação social em relação à sua origem familiar. Cabe ressaltar que o diploma de um curso superior no Brasil representa distintividade social e ganho de capital escolar.

Ainda que o PROUNI atinja apenas uma parcela da população, nota-se que tem alterado a universidade brasileira, com a inclusão de grupos sociais e étnico-raciais que historicamente eram excluídos. Também promove alterações na sociedade, com a formação qualificada, ocupação de melhores postos de trabalho, aumento da renda familiar, reduzindo os riscos de marginalização social e mitigando a infringência de Direitos Humanos. 
O ganho de capital cultural e social trazido pelo PROUNI está alinhado com a necessidade de democratização deste capital cultural para combater as grandes desigualdades socioeconômicas da sociedade brasileira. A educação se configura como uma questão central no desenvolvimento cultural e social da juventude brasileira e o ingresso das camadas com menor renda nas IES pode ser um instrumento para intervir e anunciar alterações significativas no sistema educacional do Brasil. O acesso à educação representa a garantia do direito humano e o direito fundamental à educação.

Entre as críticas estão a de que esta política garante o acesso ao ensino superior, mas não aumentou o número de vagas nas universidades públicas, favorecendo em grande medida as instituições de ensino superior privadas com a isenção dos impostos. Também não existem estatísticas oficiais da quantidade de estudantes que desistem do PROUNI e abandonam a universidade. O PROUNI prevê o acesso; porém, não assegura a permanência na IES. Talvez este seja o maior desafio a ser enfrentado por este Programa.

\section{Referências}

AGUIRRE, L. P. Educar para os Direitos Humanos. O Grande Desafio Contemporâneo. Rede Brasileira De Educação Em Direitos Humanos, 2007. Disponível em: http://www.dhnet.org.br/educar/redeedh/bib/aguirre.htm. Acesso em: 14 fev. 2019.

ALMEIDA, C.; DIAS, E. T. D. M.; PETRAGLIA, I.; RIZZO, L. A. Programa Universidade para Todos (PROUNI): Políticas públicas e inclusão social. Educação e Linguagem, v. 13, n. 21, p. 67-88, jan./jun. 2010.

BENEDEK, W.; MOREIRA, V.; GOMES, C. M. Compreender os Direitos Humanos. Coimbra: Coimbra Editora, 2014.

BOBBIO, N. A era dos direitos. Rio de Janeiro: Campus, 1992.

BONETI, L. W. Educação, exclusão e cidadania. 3 ed. Ijuí: Unijuí, 2003.

BONETI, L. W.; GISI, M. L.; FILIPAK, S. T. Do direito à Educação Superior ao desafio do acesso para todos. Diálogo Educ., Curitiba, v. 13, n. 39, p. 521-540, maio/ago. 2013.

BORDINI, A. S. J. Programa Universidade para todos: avaliação dos 10 anos de uma política de educação e a redução da vulnerabilidade social. Orientador: Valquiria Elita Renk. 2015.103 f. Dissertação (Mestrado em Bioética) - Programa de Pós-Graduação em Bioética, Pontifícia Universidade Católica do Paraná, Curitiba, 2015.

BOURDIEU, P. O poder simbólico. 5. ed. Rio de Janeiro: Bertrand Brasil, 2002.

BOURDIEU, P. Razões práticas: sobre a teoria da ação. Campinas: Papirus, 2005.

BOURDIEU, P. A distinção: crítica social do julgamento. Porto Alegre: Zouk; São Paulo: Edusp, 2008. 
BOURDIEU, P. Escritos da educação. Petrópolis: Vozes, 2016.

BRASIL. Constituição da República Federativa do Brasil de 1988. Brasília: 1988. Disponível em: http://www.planalto.gov.br/ccivil_03/constituicao/constituicao. htm. Acesso em: 8 jan. 2019.

BRASIL. Lei $\mathbf{n}^{\circ}$ 9.394, de 20 de dezembro de 1996. Estabelece as diretrizes e bases da educação nacional. Disponível em: https:/www2.camara.leg.br/legin/ fed/lei/1996/lei-9394-20-dezembro-1996-362578-publicacaooriginal-1-pl.html. Acesso em: 8 jan. 2019.

BRASIL. Lei n ${ }^{\mathbf{1 1}}$.096, de 13 de janeiro de 2005. Institui o Programa Universidade para Todos - PROUNI, regula a atuação de entidades beneficentes de assistência social no ensino superior; altera a Lei no 10.891, de 9 de julho de 2004, e dá outras providências. Disponível em: http://www.planalto.gov.br/ccivil_03/_ato20042006/2005/lei/111096.htm. Acesso em: 23 abr. 2019.

BRASIL. Decreto no 6.094, de 24 de abril de 2007. Dispõe sobre a implementação do Plano de Metas Compromisso Todos pela Educação, pela União Federal, em regime de colaboração com Municípios, Distrito Federal e Estados. 2007a. Disponível em: http://www.planalto.gov.br/ccivil_03/_ato2007-2010/2007/ decreto/d6094.htm. Acesso em: 23 abr. 2019.

BRASIL. Ministério da Educação. Plano de Desenvolvimento da Educação: razões, princípios e programas. Brasília: Ministério da Educação, 2007b. Disponível em: https://www.todospelaeducacao.org.br/conteudo/saiba-o-que-e-e-comofunciona-o-plano-de-desenvolvimento-da-educacao. Acesso em: 24 abr. 2019.

BRASIL. Lei no 12.101 de 27 de novembro de 2009. Dispõe sobre a certificação das entidades beneficentes de assistência social; regula os procedimentos de isenção de contribuições para a seguridade social. Disponível em: http://www.planalto.gov. br/ccivil_03/_Ato2007-2010/2009/Lei/L12101.htm. Acesso em: 3 jun. 2019.

BRASIL. Ministério da Educação. Resumo técnico Censo da Educação Superior 2015. 2. ed. Brasília: Instituto Nacional de Estudos e Pesquisas Educacionais Anísio Teixeira, 2018. Disponível em: http://portal.mec.gov.br/component/tags/ tag/32044-censo-da-educacao-superior. Acesso em: 24 abr. 2019.

BRASIL. Ministério da Educação. Censo da Educação Superior 2005. 2. ed. Brasília: Instituto Nacional de Estudos e Pesquisas Educacionais Anísio Teixeira, 2018.

BRASIL. Ministério da Educação. Todos pela Educação. Documento digital. 5 mar. 2018. Disponível em: https://www.todospelaeducacao.org.br/conteudo/ saiba-o-que-e-e-como-funciona-o-plano-de-desenvolvimento-da-educacao. Acesso em: 23 abr. 2019.

BRASIL. Ministério da Educação. Plano Nacional de Educação 2011 - 2020. Brasília: MEC, 2011. Disponível em: http://fne.mec.gov.br/images/pdf/notas_ tecnicas_pne_2011_2020.pdf. Acesso em: 17 fev. 2019.

CANDIOTTO, J. F.; CUSTÓDIO, P. V. P. Políticas Públicas de Educação: Seu impacto na melhoria das condições de vida da população brasileira e sua correlação com a garantia de Direitos Fundamentais. In: XIII CONGRESSO NACIONAL DE EDUCAÇÃO - EDUCERE, ? 2017, Curitiba. Anais EDUCERE[...]. Curitiba: PUC-PR, 2017. p. 17.437-17.450. Disponível em: https://educere.bruc. com.br/arquivo/pdf2017/27055_14043.pdf. Acesso em 05 mar 2019. 
CATANI, A. M.; OLIVEIRA, J. F. A educação superior. In: OLIVEIRA, R. P.; ADRIÃO, T. (Org.). Organização do ensino no Brasil: níveis e modalidades na Constituição Federal e na LDB. 2. ed. São Paulo: Xamã, 2007. p. 73-84.

CATANI, A. M.; HEY, A. P.; GILIOLI, R. S. P. PROUNI: democratização do acesso às Instituições de Ensino Superior? Educar, Curitiba, v. 28, p. 125-140, 2006.

CHAVES V. L. Expansão da privatização/mercantilização do ensino superior brasileiro: a formação de oligopólios. Educação \& Sociedade, Campinas: CEDES, v. 31, n. 111, p. 481-500, abr./jun. 2010.

CHAVES, V. L. J.; AMARAL, N. C. Política de expansão da educação superior no Brasil - o prouni e o fies como financiadores do setor privado. Educ. rev., Belo Horizonte, v. 32, n. 4, out./dez. 2016.

CHIARINI, T.; VIEIRA, K. P. Universidades como produtoras de conhecimento para o desenvolvimento econômico: sistema superior de ensino e as políticas de CT\&I. Revista Brasileira de Economia, Rio de Janeiro, v. 66, n. 1, p. 117-132, 2012.

COSTA, D. D.; FERREIRA, N. I. B. O PROUNI na educação superior brasileira: indicadores de acesso e permanência. Avaliação, Sorocaba, v. 22, n. 1, p. 141-163, mar./jun. 2017.

COSTA, F. S. O PROUNI e seus egressos: uma articulação entre educação, trabalho e juventude. Orientador: Isabel Franchi Cappeletti. 2013. $201 \mathrm{f}$. Tese (Doutorado em Educação) - Programa de Pós-Graduação em Educação, Pontifícia Universidade Católica de São Paulo, São Paulo, 2013.

CURY, C. R.J. Políticas inclusivas e compensatórias na educação básica. Cadernos de Pesquisa, v. 35, n. 124, p. 11-32, jan./abr. 2005.

CURY, C. R. J. Direito à igualdade, direito à diferença. Caderno de Pesquisa, São Paulo, n. 116, p. 245-262, jul. 2002.

CUSTÓDIO, P. V. P. O PROUNI como instrumento de democratização para o acesso às IES e a mitigação ou infração dos Direitos Humanos. Orientador: Jaci de Fátima Candiotto. 2019. 109 f. Dissertação (Mestrado em Direitos Humanos e Políticas Públicas) - Programa de Pós-Graduação em Direitos Humanos e Políticas Públicas, Pontifícia Universidade Católica do Paraná, Curitiba, 2019.

DI GIOVANNI, G. As estruturas elementares das políticas públicas. Caderno de Pesquisa, v. 82, p. 1-32, 2009.

ELY, R. ProUni converte isenção de impostos em vagas nas universidades. 2019. Disponível em: http://portal.mec.gov.br/component/content/article/40perguntas-frequentes-911936531/prouni-1484253965/3552-sp-1327306896. Acesso em: 20 maio 2019.

FOLMANN, J. I. (Org.). Dialogando com Jessé Souza. São Leopoldo: Casa Leiria, 2018.

GALLARDO, H. Teoria crítica: matriz e possibilidade de direitos humanos. Tradução de Patricia Fernandes. São Paulo: Ed. Unesp, 2014.

GARRAFA, V.; PESSINI, L. Bioética: Poder e Injustiça. São Paulo: Ed. Loyola, 2004. 
GOMES, A. M. As reformas e políticas da educação superior no Brasil: avanços e recuos. In: MANCEBO, D.; SILVA JÚNIOR, J. R.; OLIVEIRA, J. F. (Org.). Reformas políticas: educação superior e pós-graduação no Brasil. V.1. Campinas: Alínea, 2008. p. 23-51.

GUIMARÃES, J. V.; SANTOS, N. C. O Programa Universidade para Todos no Brasil. In: LIMENA, M. M. (Org.). PROUNI e Inclusão Social. São Paulo: Xamã, 2011.p. 63-86

HOSSNE, W. S. Dos referenciais da Bioética - a Vulnerabilidade. Revista Bioethikos: Centro Universitário São Camilo, v. 3, n. 1, 41-51, 2009.

INSTITUTO BRASILEIRO DE GEOGRAFIA E ESTATÍSTICA (IBGE). IBGE na Síntese de Indicadores Sociais 2018. Disponível em: https://www. ibge.gov.br/estatisticas/sociais/populacao/9221-sintese-de-indicadoressociais. html? $=\& t=$ downloads. Acesso em: 20 abr. 2019.

LIMENA, M. M.; RODRIGUES, M. L.; PETRAGLIA, I.; ALMEIDA, C. (Org.). PROUNI e inclusão social. São Paulo. Ed. Xamã, 2011.

LUCRI,J.L.Estado e Governança Educacional:Um estudo de caso do PROUNI. Orientador: .Luiz Gustavo Bambini de Assis 2016. 105 f. Dissertação (Mestrado em Análise de Políticas Públicas) - Escola de Artes, Ciências e Humanidades, Universidade de São Paulo, São Paulo, 2016.

MALISKA, M. A. O Direito à Educação e a Constituição. Porto Alegre, 2001.

MANCEBO, D. Reforma universitária: reflexões sobre a privatização e a mercantilização do conhecimento. Educ. Soc. [online], v. 25, n. 88, p. 845-866, 2004.

MARI, M. C. de. Programa Universidade para Todos: As fragilidades do sistema de bolsas para estudantes carentes. Orientador: Maria Tereza Carneiro. 2011. 66 f. Monografia (Graduação em Políticas Educacionais) - Universidade Federal do Paraná, 2011. Disponível em: http://nupe.ufpr.br. Acesso em: 14 jun. 2017.

MARQUES, E. P. S. O Prouni e a democratização do acesso à educação superior no Brasil. In: HERINGER, R. (Org.). Democratização da educação Superior no Brasil. Novas dinâmicas, dilemas, aprendizados. Cadernos do GEA, v. 7, p. 53-59, jan./jun. 2015.

MILANEZ, G. G. T. Um estudo sobre egressos do Programa Universidade Para Todos na cidade de São Paulo. Orientador: Marcia Regina de Lima Silva. 2016. 238 f. (Dissertação Sociologia ) - Faculdade de Filosofia, Letras e Ciências Humanas, Universidade de São Paulo, São Paulo, 2016.

GANISATION FOR ECONOMIC COOPERATION AND DEVELOPMENT (OECD). Education at a glance 2016 - Indicators. Disponível em: https://www.oecd.org/education/skills-beyond-school/educationat-a-glance-2016-indicators.htm. Acesso em: 24 abr. 2019.

ORGANISATION FOR ECONOMIC COOPERATION AND DEVELOPMENT (OECD). Education at a Glace. 2018a. Disponível em: https://read.oecd-ilibrary.org/education/education-at-a-glance-2018/summary/ portuguese_6777b3a7-pt\#page1. Acesso em: 15 nov. 2018.

ORGANISATION FOR ECONOMIC COOPERATION AND DEVELOPMENT (OECD). Um elevador social quebrado?. 2018b. Disponível 
em: https://www.oecd.org/brazil/social-mobililty-2018-BRA-PT.pdf. Acesso em: 10 dez. 2019.

ORGANIZAÇÃO DAS NAÇÕES UNIDAS (ONU). Declaração Universal dos Direitos Humanos (1948). Disponível em: https://nacoesunidas.org/wpcontent/uploads/2018/10/DUDH.pdf. Acesso em: 16 fev. 2019.

ORGANIZAÇÃO DAS NAÇÕES UNIDAS (ONU). Declaração e Programa de Ação de Viena. Conferência Mundial de Direitos Humanos. 1993. Disponível em: http://www.direitoshumanos.usp.br/index.php/ Sistema-Global.-Declara\%C3\%A7\%C3\%B5es-e-Tratados-Internacionais-deProte\%C3\%A7\%C3\%A3o/declaracao-e-programa-de-acao-de-viena.html. Acesso em 07 jul 2019

PAUGAM, S. Desqualificação Social: ensaio sobre a nova pobreza. São Paulo: Educ/Cortez, 2003.

PIOVESAN, F. Democracia, Direitos Humanos e Globalização Econômica: Desafios e Perspectivas para a construção da cidadania no Brasil. 2008. Disponível em: http://dhnet.org.br/direitos/militantes/flaviapiovesan/piovesan_democracia_ dh_global_economica_br.pdf. Acesso em: 16 fev. 2019.

PIOVESAN, F. Poder Judiciário e os Direitos Humanos. Revista USP, São Paulo, n. 101, p. 99-112, mar./abr./maio 2014.

PROGRAMA DAS NAÇÕES UNIDAS PARA O DESENVOLVIMENTO (PNUD). Ranking IDH Global. 2014. Disponível em: http://www.br.undp.org/ content/brazil/pt/home/idh0/rankings/idh-global.html. Acesso em: 17 jun. 2018.

PROGRAMA DAS NAÇÕES UNIDAS PARA O DESENVOLVIMENTO (PNUD). Relatório do Desenvolvimento Humano do Programa das Nações Unidas para o Desenvolvimento. 2018. Disponível em: http://www.br.undp.org/ content/brazil/pt/home/idh0.html. Acesso em: 29 jun. 2019.

RIZZOTTO, M. L. F.; BORTOLOTO, C. O conceito de equidade no desenho de políticas sociais: pressupostos políticos e ideológicos da proposta de desenvolvimento da CEPAL. Interface (Botucatu) [online], v. 15, n. 38, p. 793804, 2011.

RODRIGUES, J. Os empresários e a educação superior. Campinas: Autores Associados, 2007.

ROSA, R. C. A Garantia do Direito Humano à Educação de Qualidade: A oferta da educação infantil no Rio Grande do Sul como novo desafio do Ministério Público. Disponível em: http://www.mprs.mp.br/areas/infancia/arquivos/a_ garantia.pdf. Acesso em: 3 jun. 2016.

SACAVINO, S.; CANDAU, V. M. Educação em Direitos Humanos: Temas, questões e propostas. Petrópolis: DP et Alli Editora, 2008.

SANTOS, B. S. S. Uma concepção multicultural de direitos humanos. Editora Lua Nova, São Paulo, n. 39, p. 105-124, 1997.

SARLET, I. W. Dignidade da pessoa humana e direitos fundamentais na Constituição de 1988. 8. ed. Porto Alegre: Livraria do Advogado Editora Ltda., 2010. 
SAVIANI, D. PDE - Plano de Desenvolvimento da Educação: Análise crítica da política do MEC. Campinas: Autores Associados, 2009.

SAVIANI, D. Antecedentes, origem e desenvolvimento da pedagogia históricocrítica. In: MARSIGLIA, A. C. G. (Org.). Pedagogia histórico-crítica: 30 anos. Campinas: Autores Associados, 2011.p. 197-225.

SEVERINO, A. J. O ensino superior brasileiro: novas configurações e velhos desafios. Curitiba: Editora UFPR, 2008.

SERAFIM, M. P. O Processo de Mercantilização das Instituições de Educação Superior: Um Panorama do Debate nos EUA, na Europa e na América Latina. Avaliação, Sorocaba, SP, v. 16, n. 2, p. 241-265, jul. 2011.

SCHRAMM, F. R. A Bioética de proteção é pertinente e legitima? Revista Bioética, v. 19, n. 3, p. 713-24, 2011.

SCHWARTZMAN, S. Pobreza, exclusão social e modernidade: uma introdução ao mundo contemporâneo. São Paulo: Augurium Editora, 2004.

SOUZA, C. Políticas Públicas: uma revisão da literatura. Sociologias, Porto Alegre, ano 8, n. 16, p. 368-375, jul./dez 2006.

SOUZA, J. A tolice da inteligência brasileira: ou como o país se deixa manipular pela elite. São Paulo: LeYa, 2015.

SOUZA, P. H. G. F. A desigualdade vista do topo: a concentração de renda entre os ricos no Brasil. 1926-2013. Orientador: Marcelo Medeiros Coelho de Souza. 2016. 378f. (Tese). Doutorado Sociologia) -Instituto de Ciências Sociais. Universidade de Brasília. 2016.

SPELLER, P.; ROBL, F.; MENEGHEL, S. M. (Org.). Desafios e perspectivas da educação superior brasileira para a próxima década. Brasília: UNESCO, CNE, MEC, 2012.

SYMONIDES, J. (Org.). Direitos humanos: novas dimensões e desafios. Brasília: UNESCO; Secretaria Especial dos Direitos Humanos, 2003.

TEIXEIRA, E. M. S. F. Análise do PROUNI como Política Pública Afirmativa. 2015. Revista Juridica Unicuritiba, v. 4, n. 41, p. 176-206, 2015.

TREVISAN, A. P.; BELLEN, H. M. V . Avaliação de políticas públicas: uma revisão teórica de um campo em construção. Revista de Administração Pública, Rio de Janeiro, v. 42, n. 3, p. 529-550, 2008.

VALLE, M. J. PROUNI: política pública de acesso ao ensino superior ou privatização? Orientador: Anita Helena Schlesener. 2009. 110 f. Dissertação (Mestrado em Educação) - Programa de Pós-Graduação em Educação, Universidade Tuiuti, Curitiba, 2009.

Submetido: 04/06/2019.

Aceito: 08/07/2019. 


\title{
PROUNI: HIGHER EDUCATION POLICIES 10 YEARS LATER
}

\begin{abstract}
University for all Program (PROUNI) has been in effect since 2005 enabling the access of low income students to Private Higher Education Institutions with scholarships. In this article aimed to evaluate the efficacy of the program through the socio-economic situation of 352 candidates who are graduates in the healthcare area of a Private Higher Education Institution of Curitiba, that welcomes students from all over the country, from 2005 to 2015. It is a mixed approach research of a descriptive character and the research instrument is a questionnaire covering socio-demographic questions, importance of Prouni and what were the difficulties encountered to attend graduation. The results showed that the majority of graduates are women, are inserted in the formal labor market, in the area of training, receive remuneration exceeding five minimum wages and are the first people on their family to complete Higher Education. The participants reported difficulties in completing the undergraduate course, such as situations of prejudice and financial difficulties. This program promoted the access and completion of Higher Education to thousands of lowincome youths, their social inclusion, increasing their social capital, decreasing situations of social vulnerability and promoting human dignity. But it still presents dilemmas such as the non-guarantee of permanence of the student in the educational institution, the non-expansion of vacancies in Public HEI and the benefit that Private Institutions have with tax exemption. The results are discusses in the interdisciplinary perspective between education, sociology and human rights.
\end{abstract}

Keywords: Education. Public Policies. Higher Education.

\section{PROUNI: POLÍTICA DE ACCESO A LA ENSEÑANZA SUPERIOR 10 AÑOS DESPUÉS}

\section{Resumen}

Programa de la Universidad para Todos (PROUNI) ha estado vigente desde 2005, brindando acceso a las Instituciones Privadas de Educación Superior para estudiantes de bajos ingresos con la concesión de becas. En este artículo que tuvo como objetivo evaluar la eficacia del programa, a través de la condición socioeconómica de los 352 graduados de la salud de una institución de educación superior privada en Curitiba, que recibe estudiantes de todo el país, de 2005 a 2015. Se trata de un enfoque de investigación y el instrumento de investigación es un cuestionario que cubre cuestiones sociodemográficas, la importancia de PROUNI y las dificultades encontradas en los estudios de pregrado. Los resultados muestran que la mayoría de los graduados son mujeres, se insertan en el mercado laboral formal, área de entrenamiento, recibir pago superior a cinco salarios mínimos y son el primer miembro de la familia para completar un grado. Los participantes reportaron dificultades para completar el curso de pregrado, como situaciones de prejuicio y dificultades financieras. Este programa promueve el acceso y la conclusión de la educación superior a miles de jóvenes de bajos ingresos, la inclusión social, el aumento de su capital por la disminución de las situaciones de vulnerabilidad social y la promoción de la dignidad humana. Pero también presenta dilemas como ninguna garantía de estudiante de permanencia en la institución educativa, para no aumentar la matrícula en las instituciones públicas de educación superior y el beneficio para las instituciones educativas privadas con exención de impuestos. Los resultados se discuten en una perspectiva interdisciplinaria entre educación, sociología y derechos humanos.

Palabras clave: Educación. Políticas públicas. Educación superior. 